\title{
TEMPRANA EVIDENCIA DE PATOLOGÍA OCULAR EN LA CERÁMICA PREHISPÁNICA
}

\author{
BERNAL JE ${ }^{1}$, BRICEÑO I ${ }^{2}$
}

Tumaco-La Tolita es el nombre dado a un complejo cultural que habitó el sur de Colombia y el norte del actual Ecuador; su verdadero nombre está perdido en el tiempo; ya extinto a la llegada de los Españoles a América, este grupo mantuvo su identidad cultural por cerca de 1000 años entre el siglo VI a.C. y el siglo V de nuestra era. Miles de artefactos de cerámica son casi los únicos remanentes de esta cultura, y en ellos dejaron representados su vida y su mundo, incluyendo su comportamiento sexual, atuendos, arquitectura, cosmogonía y diversa patología genética y no genética (1), que asombra por la fidelidad de sus detalles, por su capacidad de distinguir lo normal de lo anormal y por su clara capacidad semiológica. En lo que hace referencia al ojo presentamos aquí tres piezas; en la figura 1 podríamos pensar en una ptosis palpebral unilateral; en la figura 2 se observa una hipoplasia del pabellón auricular con una desviación de la fisura palpebral del mismo lado, que podrían corresponder a una displasia óculo-aurículo-vertebral y en la figura 3 la

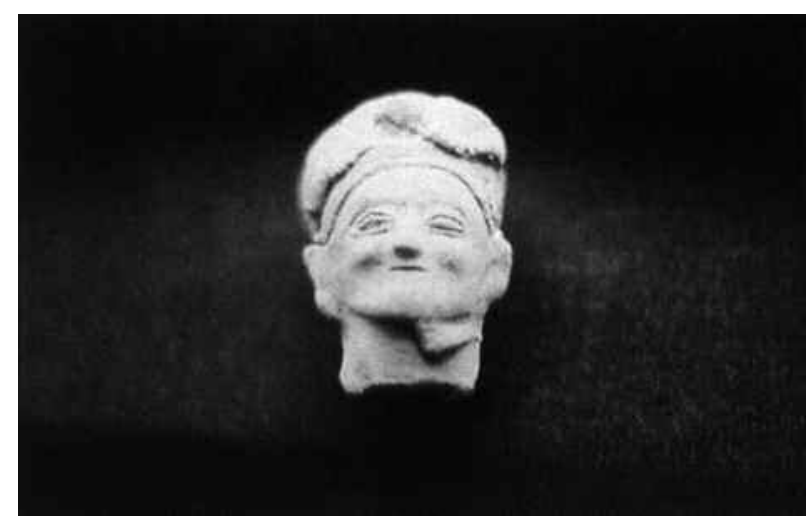

Fig. 1: Ptosis palpebral. clara evidencia de un estrabismo. Dado que estas piezas tienen cerca de dos mil años, es probable que sean las más antiguas expresiones de la existencia de estas patologías.

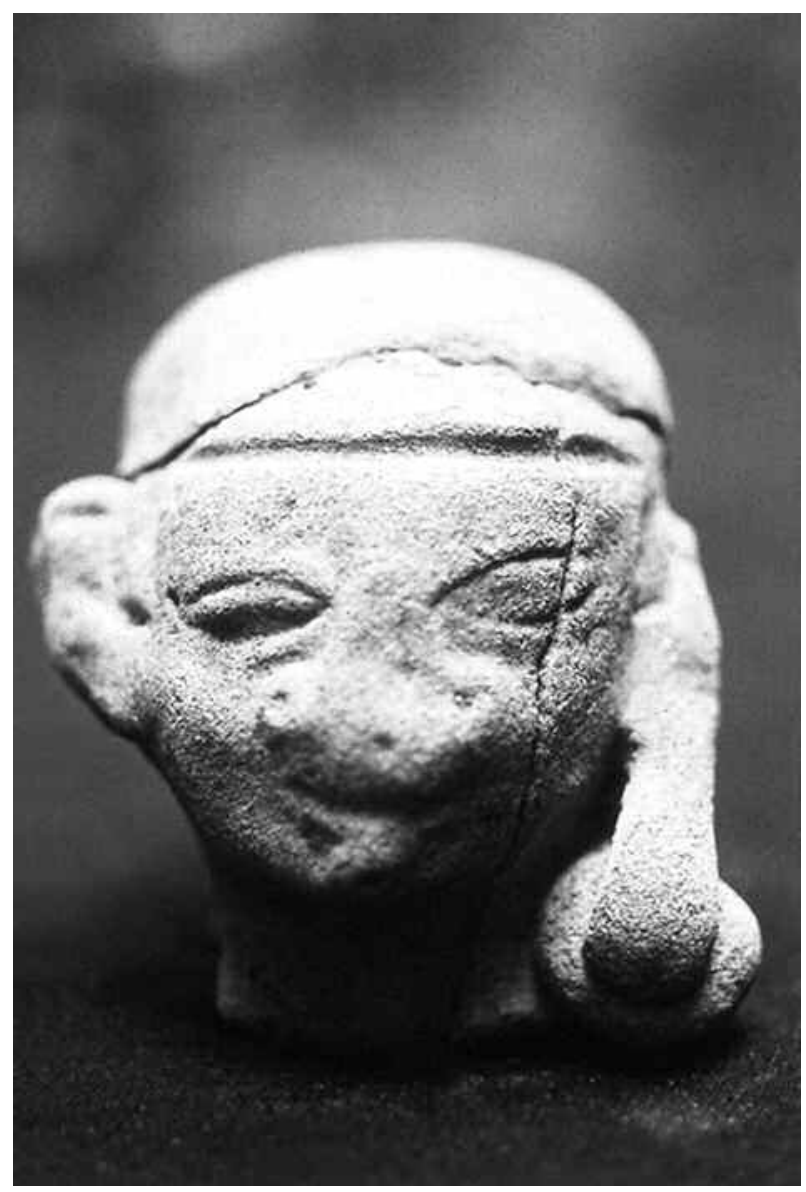

Fig. 2: Displasia óculo-aurículo-vertebral.

\footnotetext{
Instituto de Genética Humana. Facultad de Medicina. Pontificia Universidad Javeriana. Bogotá, Colombia.

1 Doctor en Medicina, PhD en genética humana.

E-mail: jebernal@javeriana.edu.co
} 


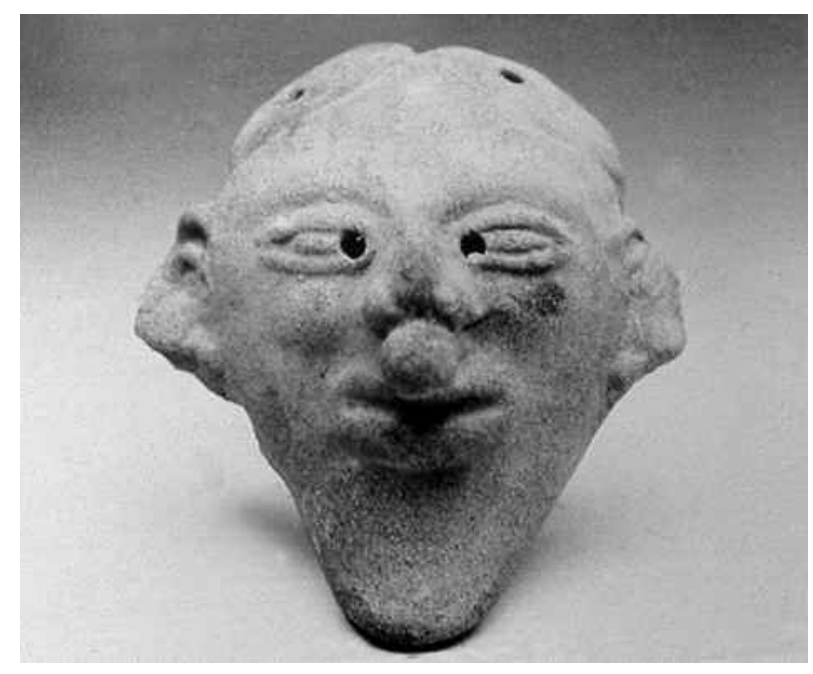

\section{BIBLIOGRAFÍA}

1. Bernal JE, Briceño I. Genetic and other diseases in the pottery of Tumaco-La Tolita culture in Colombia-Ecuador. Clin Genet 2006; 70: 188-191.

Fig. 3: Estrabismo. 